\title{
Small-Scale Isolation of Viral RNA-Dependent RNA Polymerase from Protoplasts Inoculated with In Vitro Transcripts
}

\author{
Scott Adkins and Dennis J. Lewandowski
}

First author: U.S. Department of Agriculture, Agricultural Research Service, United States Horticultural Research Laboratory, 2001 South Rock Road, Fort Pierce, FL 34945; and second author: Department of Plant Pathology, University of Florida, Citrus Research and Education Center, 700 Experiment Station Road, Lake Alfred 33850.

Accepted for publication 24 April 2001.

\begin{abstract}
Adkins, S., and Lewandowski, D. J. 2001. Small-scale isolation of viral RNA-dependent RNA polymerase from protoplasts inoculated with in vitro transcripts. Phytopathology 91:747-752.

Cowpea chlorotic mottle virus (CCMV) replicated in tobacco suspension cell protoplasts inoculated with in vitro transcripts of CCMV RNA1, 2, and 3. CCMV RNA-dependent RNA polymerase (RdRp) isolated from these protoplasts specifically recognized CCMV and Brome mosaic virus (BMV) subgenomic RNA promoters and directed in vitro RNA synthesis in a manner indistinguishable from CCMV RdRp more laboriously isolated from systemically infected cowpea leaves. Omission of CCMV RNA3 from the protoplast inoculum or replacement with in vitro tran-

scripts of BMV RNA3 reduced CCMV (+)-strand RNA1 and 2 accumulation to $\approx 1 / 40$ and $\approx 1 / 10$, respectively, of the level attained when CCMV RNA3 was present. The absence of CCMV RNA3 did not prevent assembly and isolation of highly active, template-dependent and templatespecific CCMV RdRp, which directed synthesis of products identical in size to those of RdRp isolated from protoplasts inoculated with all three CCMV genomic RNAs. These results demonstrate that CCMV RNA1 and 2 are sufficient for CCMV replication and RdRp assembly in tobacco protoplasts. This approach for isolation of functional viral RdRp will be especially useful for viruses for which large quantities of infected tissue are unavailable, such as those with specific tissue tropisms or mutants incapable of systemic movement.
\end{abstract}

Most plant viruses have single-stranded RNA genomes and thus require an RNA-dependent RNA polymerase (RdRp), an enzyme complex composed of viral and cellular proteins, to direct their replication (7). Mechanistic details of viral RNA-dependent RNA synthesis are only now emerging from model plant virus systems for which highly enriched viral RdRps capable of recognizing exogenous templates containing viral promoter sequences have been isolated $(14,22)$. Plant virus RdRps are generally isolated from systemically infected leaf tissue $(1,28,33)$. Highly enriched bromoviral RdRps can synthesize subgenomic RNA4 from exogenously added (-)-strand RNA3 $(1,19)$ and $(-)$-strand RNAs from (+)-strand RNAs $(12,21)$ in a sequence-specific manner. Initiation of bromoviral subgenomic RNA synthesis can be reproduced with well-characterized minimal templates known as proscripts (1,2,32). A proscript containing the 20-nucleotide (nt) core subgenomic promoter and the initiation nucleotide is sufficient to direct accurate bromovirus transcription $(1,32)$. In this report, we examined the ability of tobacco suspension cell protoplasts to support replication of the bromovirus Cowpea chlorotic mottle virus (CCMV), and to serve as a source of CCMV RdRp for in vitro studies. We demonstrate the usefulness of this system for rapid isolation of highly active, template-dependent and template-specific viral RdRp from protoplasts. We show that CCMV RNA1 and RNA2 are sufficient for assembly and isolation of CCMV $\mathrm{RdRp}$ that directs synthesis of products of the identical size to those synthesized by CCMV RdRp isolated from tissue infected with the wild-type virus.

Corresponding author: S. Adkins; E-mail address: SAdkins@ushrl.ars.usda.gov

Publication no. P-2001-0523-01R

This article is in the public domain and not copyrightable. It may be freely reprinted with customary crediting of the source. The American Phytopathological Society, 2001.

\section{MATERIALS AND METHODS}

Protoplast inoculation and analysis of viral RNA. RNA was synthesized in vitro from XbaI-linearized pCC1TP1, pCC2TP2, and pCC3TP4 (6) or EcoRI-linearized pB3TP8 (13) as previously described (16). Protoplasts were prepared from a Nicotiana tabacum cv. Xanthi suspension cell line as previously described (17). Protoplasts were suspended at $2 \times 10^{6}$ cells per $750 \mu \mathrm{l}$ in $500 \mathrm{mM}$ D-mannitol, $70 \mathrm{mM} \mathrm{KCl}$, and $5 \mathrm{mM}$ 2-(4-morpholino)-

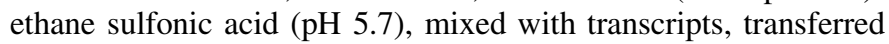
to a cold 4-mm gap cuvette, and electroporated at a setting of $625 \mathrm{~V} / \mathrm{cm}$ with a $125-\mu \mathrm{F}$ capacitor using a Gene Pulser (Bio-Rad, Hercules, CA). Eight aliquots of $\approx 2 \times 10^{6}$ protoplasts were separately inoculated with one eighth of a 100- $\mu \mathrm{l}$ T7 in vitro transcription reaction of each of the relevant transcripts and subsequently pooled. Total RNA was extracted at $\approx 20 \mathrm{~h}$ postinoculation, denatured, separated by electrophoresis on formaldehyde gels, and analyzed by northern blot hybridization as previously described (16). Positive- and negative-strand RNAs were detected with digoxigenin-labeled RNA probes complementary to (6) or corresponding to a conserved CCMV RNA3 3'-DraI-XbaI fragment.

Preparation of templates for RdRp activity assays. Pairs of overlapping primers, one containing a T7 promoter, were used for polymerase chain reaction amplification of cDNA copies of (-)strand CCMV or Brome mosaic virus (BMV) RNA3 encompassing the subgenomic promoter as previously described (1). Proscripts were synthesized by T7 RNA polymerase (Ampliscribe, Epicentre Technologies, Madison, WI) as previously described (2) and gel-purified to remove nucleoside triphosphates and proteins. CCMV and BMV virion RNAs were isolated from virion preparations according to previously described methods (25). Proscripts were inspected by denaturing polyacrylamide gel electrophoresis, virion RNAs were inspected by native agarose gel electrophoresis, and both types of RNAs were quantified by UV absorbance. 
Isolation of RdRps. CCMV RdRp was prepared from systemically infected cowpea leaves as previously described $(1,31,33)$, and RdRps were prepared from mock- or in vitro transcript-inoculated protoplasts with a small-scale adaptation of this method. Protoplasts $\left(\approx 1.5 \times 10^{7}\right)$ were pelleted at $100 \times g$ for $3 \mathrm{~min}$ at room temperature in a clinical centrifuge. The remainder of the procedure was completed at $4^{\circ} \mathrm{C}$. The cell pellet was suspended in $10 \mathrm{ml}$ of homogenization buffer consisting of $50 \mathrm{mM}$ Tris- $\mathrm{HCl}(\mathrm{pH} \mathrm{8.2)}$, $15 \mathrm{mM} \mathrm{MgCl} 2,10 \mathrm{mM} \mathrm{KCl}, 1 \mathrm{mM}$ EDTA (pH 8), 15\% (vol/vol) glycerol, $24 \mu \mathrm{g} / \mathrm{ml}$ phenylmethylsulfonyl fluoride (PMSF), and $0.01 \%$ (vol/vol) $\beta$-mercaptoethanol (BME) (31). Protoplasts were disrupted with a Dounce homogenizer and centrifuged at $1,500 \times g$ for $10 \mathrm{~min}$. The supernatant was centrifuged at $30,000 \times g$ for $20 \mathrm{~min}$ to pellet the membrane fraction, which was suspended in $10 \mathrm{ml}$ of wash buffer (83 mM Tris- $\mathrm{HCl}[\mathrm{pH} 8.2], 17 \mathrm{mM} \mathrm{MgCl}$, $35 \%$ [vol/vol] glycerol, $500 \mathrm{mM} \mathrm{KCl}, 137 \mu \mathrm{M}$ PMSF, and $0.1 \%$ [vol/vol] BME; modified from 31,33) and centrifuged at 100,000 $\times$ $g$ for $30 \mathrm{~min}$. The final pellet was solubilized by suspension in $200 \mu \mathrm{l}$ of solubilization buffer ( $83 \mathrm{mM}$ Tris- $\mathrm{HCl}$ [pH 8.2], $17 \mathrm{mM}$ $\mathrm{MgCl}_{2}, 35 \%$ [vol/vol] glycerol, $0.75 \%$ [vol/vol] Triton X-100, $750 \mathrm{mM} \mathrm{KCl}$, and $10 \mathrm{mM}$ dithiothreitol [DTT]; modified from 31,33) and incubated for $15 \mathrm{~min}$. Samples were desalted by applying 100- $\mu$ l aliquots to spin columns (Micro Bio-Spin 6; Bio-Rad) equilibrated in buffer $(50 \mathrm{mM}$ Tris- $\mathrm{HCl}[\mathrm{pH} 8.2], 10 \mathrm{mM} \mathrm{MgCl}$, $50 \mathrm{mM} \mathrm{KCl}, 25 \%$ [vol/vol] glycerol, $0.75 \%$ [vol/vol] Triton X-100, $2 \mathrm{mM}$ DTT, and $137 \mu \mathrm{M}$ PMSF; modified from 31) and centrifuging at 4,000 rpm in a microcentrifuge. Three $100-\mu \mathrm{l}$ washes with this buffer were made in the same manner, and the flowthrough was collected for RdRp activity assays. Initial assays revealed that most of the RdRp activity was located in the first wash (data not shown) and thereafter, this fraction was routinely used for assays.

RdRp activity assays and product analysis. Standard assays with all RdRp preparations consisted of $43-\mu$ l reactions containing $20 \mathrm{mM}$ sodium glutamate ( $\mathrm{pH} 8.2), 4 \mathrm{mM} \mathrm{MgCl}_{2}, 12 \mathrm{mM}$ DTT, $0.5 \%$ (vol/vol) Triton X-100, $2 \mathrm{mM} \mathrm{MnCl}_{2}, 200 \mu \mathrm{M}$ ATP, $500 \mu \mathrm{M}$ GTP, $200 \mu \mathrm{M}$ UTP, $121 \mathrm{nM}\left[\alpha_{-}{ }^{32} \mathrm{P}\right] \mathrm{CTP}(800 \mathrm{Ci} / \mathrm{mmol}, 10 \mathrm{mCi} / \mathrm{ml}$, $\mathrm{NEN}$ ), 0.5 pmol proscript or $0.5 \mu \mathrm{g}$ of virion RNA, and $10 \mu \mathrm{l}$ of $\mathrm{RdRp}$ (representing $\approx 64 \mathrm{mg}$ fresh weight of infected cowpea leaf tissue for the leaf-derived RdRp). Reactions were incubated at $30^{\circ} \mathrm{C}$ for $90 \mathrm{~min}$ and stopped by phenol-chloroform extraction followed by ethanol precipitation with $7.5 \mu \mathrm{g}$ of glycogen. Proscript RdRp products were separated by electrophoresis on denaturing (7 M urea) $20 \%$ polyacrylamide gels. Virion RNA RdRp products were treated with 2.5 units of S1 nuclease (Promega, Madison, WI) in the manufacturer's buffer at $30^{\circ} \mathrm{C}$ for $10 \mathrm{~min}$ and separated by electrophoresis on nondenaturing $1 \%$ agarose gels that were subsequently dried. All gels were wrapped in plastic and exposed to X-ray film at $-80^{\circ} \mathrm{C}$.

\section{RESULTS}

CCMV replicates in tobacco suspension cell protoplasts. Since their first enzymatic isolation (9), protoplasts have been a benefit to plant virology because they permit one-step virus growth experiments, which are difficult to duplicate in whole plants (34). Protoplasts derived from a N. tabacum cv. Xanthi suspension cell line have recently been used to aid in understanding Tobacco mosaic virus (TMV) replication, including investigations of replication-defective RNAs still capable of being replicated in trans by $\operatorname{TMV}(8,16)$ and functional analysis of the 126- and $183-\mathrm{kDa}$ TMV proteins (17). We examined the ability of these tobacco suspension cell protoplasts to support CCMV replication following coinoculation with in vitro transcripts of CCMV RNA1, RNA2, and RNA3 (Fig. 1A). High levels of CCMV RNA1, 2, and 3 and subgenomic RNA4 were detected at $20 \mathrm{~h}$ postinoculation in these cells $(\mathrm{C} 1+2+3)$ by northern blot hybridization (Fig. 1B, lane 2). No CCMV RNA was detected in mock-inoculated protoplasts (Fig. 1B, lane 1).
CCMV RdRp can be isolated from infected tobacco suspension cell protoplasts. Following our confirmation of CCMV replication in tobacco suspension cell protoplasts (Fig. 1B), we attempted to isolate viral $\mathrm{RdRp}$ from the protoplasts. Typically, RdRp isolation requires hundreds of grams of infected plant tissue, several cycles of differential centrifugation, density gradients or size exclusion chromatography, and multiple days. We wanted to streamline this procedure with the use of standard laboratory equipment to permit simultaneous isolation of many small-scale RdRp preparations. Briefly, protoplasts were collected by centrifugation, disrupted with a Dounce homogenizer, subjected to a single differential centrifugation, solubilized, and desalted on a commercial spin column. Initial assays revealed that most of the RdRp activity was located in the first spin column wash (data not shown).

Fractions collected from protoplasts were assayed for CCMV RdRp activity with previously described proscripts (1; Fig. 1C). The CCMV wild-type proscript C-20/11 is a 31-nt RNA complementary to nucleotides 1330 to 1359 of CCMV (+)-strand RNA3 (6) plus one nonviral $5^{\prime}$ guanylate and directs synthesis of an 11-nt RdRp product (1). A corresponding proscript with an initiation nucleotide transversion $(\mathrm{C}+1 \mathrm{C} / \mathrm{G})$ was used to determine whether initiation was accurate. CCMV and BMV RdRps recognize and utilize heterologous bromoviral templates both in vitro and in vivo $(1,6,20,21)$. Therefore, we also assayed for CCMV RdRp activity with a 33-nt BMV wild-type proscript (B-20/13), which is complementary to nucleotides 1222 to 1252 of BMV (+)-strand RNA3 (5), includes two nonviral $5^{\prime}$ guanylates and directs synthesis of a 13 -nt RdRp product $(1,32)$.

The first spin column wash of $\mathrm{C} 1+2+3$ protoplast extracts contained CCMV RdRp that could accurately initiate subgenomic RNA synthesis from both C-20/11 and B-20/13 (Fig. 1D, lanes 6 and 8 ). The products synthesized were identical in size to those synthesized by CCMV RdRp isolated from systemically infected cowpea leaves (Fig. 1D, lanes 10 and 12). In this and all subsequent assays, RdRp preparations from protoplasts synthesized $\approx 3$ - to 10 -fold more product than RdRp preparations isolated from leaf tissue (Fig. 1D, lanes 6 and 8 versus 10 and 12). The expected 11-nt product from C-20/11 was observed although the predominant products synthesized by the CCMV RdRp isolated from protoplasts and infected leaves were 1 and 2 nts larger than expected (12 and 13 nts, respectively) (Fig. 1D, lanes 6 and 10). The 12-nt product resulted from the nontemplated addition of $1 \mathrm{nt}$ as previously observed with both CCMV and BMV RdRps isolated from infected leaves (1). The 13-nt product could have resulted from either nontemplated addition of 2 nts or initiation at the -1 position using the uridylate in the CCMV template and the nontemplated addition of a single nucleotide, a phenomenon previously observed with both CCMV and BMV RdRps (1). The amount of $n+213$-nt product was greater than previously observed, although the same leaf RdRp preparation and CCMV proscript were used in this and a preceding report (3; Fig. 1).

The expected 13-nt product from B-20/13 was observed although the predominant product was $1 \mathrm{nt}$ larger than expected (14 nts) (Fig. 1D, lanes 8 and 12) also due to the nontemplated addition of a single nucleotide as seen previously $(1,3,32)$. No 11- to 13 -nt products were observed from $\mathrm{C}+1 \mathrm{C} / \mathrm{G}$ (Fig. $1 \mathrm{D}$, lanes 7 and 11), indicating that initiation from $\mathrm{C}-20 / 11$ occurred at the authentic initiation site used in vivo. No products were observed in the absence of exogenous template (Fig. 1D, lanes 5 and 9), indicating that the RdRp was template-dependent. No RdRp activity was isolated from mock-inoculated protoplasts (Fig. 1D, lanes 1 to 4$)$.

CCMV RNAs 1+2 are sufficient to direct replication in tobacco suspension cell protoplasts. The ability to define the protoplast inoculum in this system, and hence, the viral components of the RdRp, allows insight into the mechanism of viral RNA-dependent RNA synthesis difficult to obtain with other experimental approaches. A straightforward example is the coinocu- 
lation of protoplasts with in vitro transcripts of CCMV RNA1 and RNA2 $(\mathrm{C} 1+2)$ (Fig. 2A and B), which encode the viral protein components of the RdRp complex (4; Fig. 1A). Northern blot hybridization clearly demonstrated replication of these two RNAs in the absence of CCMV RNA3 (Fig. 2A and B, lanes 4 and 3, respectively). However, (+)-strand CCMV RNA1 and RNA2 accumulated to $\approx 1 / 40$ the level attained in the presence of CCMV RNA3 $(\mathrm{C} 1+2+3)$ (Fig. 2A, lane 4 versus 2), whereas (-)-strand CCMV RNA1 and RNA2 accumulated to approximately one half the level attained in the presence of CCMV RNA3 (Fig. 2B, lane
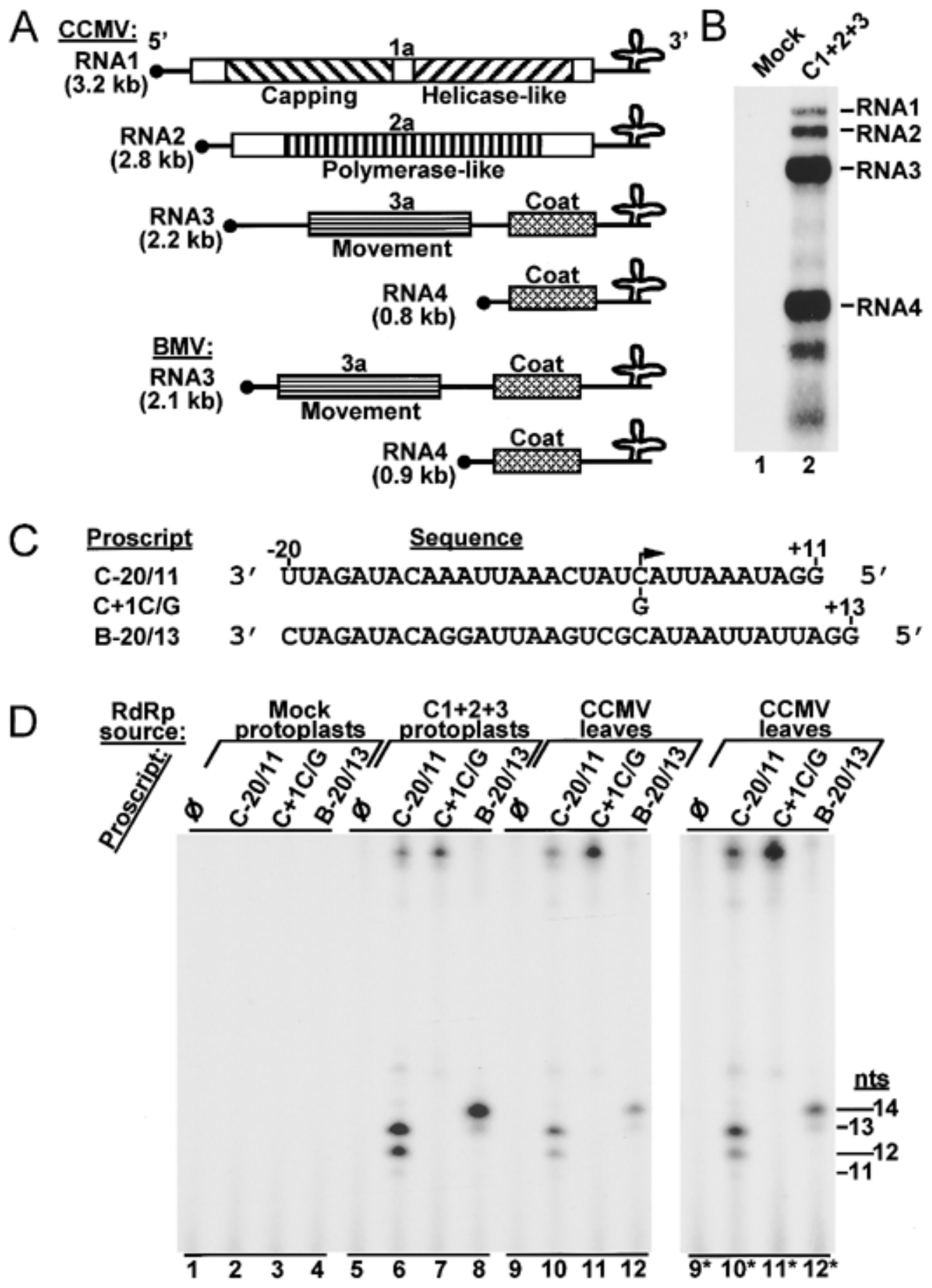

Fig. 1. Replication of Cowpea chlorotic mottle virus (CCMV) in tobacco protoplasts and isolation of active RNA-dependent RNA polymerase (RdRp). A, Schematic of CCMV RNA1 to 4 and Brome mosaic virus (BMV) RNA3 and 4 where solid lines represent untranslated regions and open boxes indicate reading frames for the four viral proteins (1a, 2a, 3a, and coat). Motifs/functions of proteins are indicated adjacent to reading frames. $5^{\prime}$ caps (solid circles) and $3^{\prime}$ tRNA-like structures are indicated. Subgenomic RNA4 is derived from internal initiation on (-)-strand RNA3 in both viruses. B, Northern blot of total RNA extracted at $20 \mathrm{~h}$ postinoculation from tobacco protoplasts mock-inoculated or inoculated with in vitro transcripts of CCMV RNA1, 2, and $3(\mathrm{C} 1+2+3)$. Positions of the four CCMV RNAs are indicated. The sequences of the additional bands in the inoculated samples are unknown. $\mathbf{C}$, Sequences of wild-type CCMV (C-20/11) and BMV (B-20/13) proscripts are shown with the initiation nucleotide (nt; +1) indicated with an arrow. The C to G transversion in the CCMV +1 initiation mutant is indicated for proscript C $+1 \mathrm{C} / \mathrm{G}$. D, Products synthesized in vitro by CCMV RdRp isolated from tobacco protoplasts or cowpea leaves. The RdRp source and proscript template for each reaction are indicated above the autoradiograph. Lane $\emptyset$ represents the products of a control reaction with no added template. RdRp products were separated by denaturing polyacrylamide gel electrophoresis and visualized by autoradiography ( $5 \mathrm{~h}$ exposure). Sizes of products in nucleotides (nts) are indicated. Sizes were estimated by comparison with products of established sizes synthesized by the BMV RdRp from these same templates (1). Lanes $9 *$ to $12 *$ are a 9 -h exposure of lanes 9 to 12. 
3 versus 1 when double-stranded (ds) RNA1 and 2 in lane 1 are considered). These results indicate that the effects of CCMV RNA3 on replication in these cells were similar to those observed with BMV in barley protoplasts and CCMV in cowpea protoplasts $(10,18,29)$.

The capacity to examine the ability of BMV RNA3 to replace CCMV RNA3 (Fig. 2A and B) is another example of the utility of this protoplast system, because this combination does not lead to systemic infection of cowpea plants (6). In the presence of BMV RNA3 (C1+2+B3) (Fig. 2A and B, lanes 3 and 2, respectively), $(+)$-strand CCMV RNA1 and RNA2 accumulated to $\approx 1 / 10$ the level observed in the presence of CCMV RNA3 $(\mathrm{C} 1+2+3)$ (Fig. 2A, lane 1) and (-)-strand CCMV RNA1 and RNA2 accumulated to approximately one-half the level attained in the presence of CCMV RNA3 (Fig. 2B, lane 1 when dsRNA1 and 2 in lane 1 are considered). Although the addition of BMV RNA3 did not restore CCMV replication to wild-type levels, it did increase accumulation of (+)-strand CCMV RNA1 and 2 by approximately fourfold compared with CCMV RNA1 and 2 alone (Fig. 2A, lane 3 versus 4 ), similar to results obtained in barley protoplasts (6). Addition of BMV RNA3 slightly reduced accumulation of (-)-strand CCMV RNA1 and 2 (Fig. 2B, lane 2 versus 3).

CCMV RNAs 1+2 are sufficient for assembly of functional and isolatable CCMV RdRp. To determine whether extractable CCMV RdRp was affected by the absence of RNA3 or the presence of a heterologous RNA3, CCMV RdRp was isolated from tobacco protoplasts transfected with in vitro transcripts of CCMV RNA1 and $2(\mathrm{C} 1+2)$ or CCMV RNA1 and 2 plus BMV RNA3 $(\mathrm{C} 1+2+\mathrm{B} 3)$. $\mathrm{RdRp}$ isolated from $\mathrm{C} 1+2$ protoplasts could accurately initiate subgenomic RNA synthesis from both C-20/11 and B-20/13 (Fig. 2C, lanes 10 to 12 ). The products were identical in size to those synthesized from the proscripts by CCMV RdRp isolated from both $\mathrm{C} 1+2+3$ protoplasts (Fig. 2C, lanes 6 to 8 ) and systemically infected cowpea leaves (Fig. 2C, lanes 18 to 20). CCMV RdRp isolated from $\mathrm{C} 1+2+\mathrm{B} 3$ protoplasts also directed synthesis of products identical in size (Fig. 2C, lanes 14 to 16) to those observed with CCMV RdRp assembled in the presence of CCMV RNA3. No products were observed in the absence of exogenous template (Fig. 2C, lanes 5, 9, 13, and 17). These results demonstrate that CCMV RNA3 is not required for assembly of functional and isolatable CCMV RdRp in this system. However, CCMV RdRp assembled in the absence of CCMV RNA3 synthesized slightly reduced amounts of subgenomic products compared with CCMV RdRp assembled in the presence of CCMV RNA3 (Fig. 2C, lanes 10, 12, 14, and 16 versus lanes 6 and 8).

Each protoplast RdRp preparation was examined for its ability to direct (-)-strand RNA synthesis from CCMV and BMV virion RNAs. These virion RNAs function as templates for both CCMV and BMV RdRps isolated from infected leaf material $(21,31)$. The (-)-strand RNA product profiles synthesized by CCMV RdRp isolated from protoplasts inoculated with the different combinations of in vitro transcripts were identical to each other (Fig. 2D, lanes $5,8,11$, and $6,9,12$ ) and to the product profiles synthesized by CCMV RdRp isolated from systemically infected cowpea leaves (Fig. 2D, lanes 14 and 15). However, the relative amounts of products varied between RdRp sources. RdRp prepared from $\mathrm{C} 1+2+3$ protoplasts made most effective use of bromovirus (+)strand RNA4 for (-)-strand synthesis (Fig. 2D, lanes 5 and 6). RdRp prepared from $\mathrm{C} 1+2$ protoplasts did not effectively utilize bromovirus (+)-strand RNA3 for (-)-strand synthesis (Fig. 2D, lanes 8 and 9). In the absence of exogenous template, very low levels of (-)-strand RNA were synthesized from endogenous templates (Fig. 2D, lanes 4, 7, and 10). No (-)-strand RNA3 and 4 products were present unless template was added to preparations of $\mathrm{RdRp}$ isolated from $\mathrm{C} 1+2$ protoplasts (Fig. 2D, lane 7). This result is consistent with the northern blots (Fig. 2A and B, lanes 4 and 3, respectively) and demonstrates that RdRp can be isolated from protoplasts containing no replicating RNA3 and 4.

\section{DISCUSSION}

The general approach for isolation of viral RdRps outlined in this report should be useful to scientists investigating multiple aspects of viral RNA replication through in vitro RNA synthesis experiments. Bromoviruses have long been known to replicate in protoplasts $(23,24)$. Previous research has shown that bromovirus RNA1 and 2 can direct their own replication in protoplasts $(15,18,29)$ and that crude membrane-bound polymerase activities can be isolated from protoplasts inoculated with physically separated genomic RNA1 and 2 of viruses in the Bromoviridae, including BMV (27) and Cucumber mosaic virus (26). However, these crude polymerase preparations were template-independent, indicating that they were isolated with a bound template $(26,27)$. The inability to use exogenous templates limits the use of such enzyme preparations for in vitro studies of viral RNA synthesis, and physical separation of viral genomic RNAs is neither as precise nor as practical as the use of in vitro transcripts. Transgenic expression of (35) and addition of affinity tags to (11) viral replication proteins have also been tested as alternative sources of viral RdRp complexes for RNA synthesis studies. These approaches are limited because they require plant transformation or modifications of viral open reading frames that may affect protein function.

The approach we report here overcomes the previously mentioned limitations and permits rapid isolation of small quantities of template-dependent and template-specific viral RdRps. We demonstrated the utility of this approach by addressing a basic question of viral RNA replication (i.e., is CCMV RNA3 required for assembly of isolatable CCMV RdRp?) that would be difficult to test with whole plants as the source of RdRp. Time and labor savings are significant compared with preparation of large quantities of infected plant tissue. The synchronous nature of viral replication in protoplasts likely results in a greater percentage and uniformity of virus-infected cells than in systemically infected leaf tissue and may partially explain the higher levels of RNA synthesis by our protoplast RdRp preparations. Separate pools of protoplasts, each infected with a different virus, a different mutant of a single virus or various combinations of genomic RNAs could provide a ready source for rapid isolation of small quantities of viral RdRps and eliminate the need for plant material infected with each type of virus. This would be especially critical for mutants that cannot move systemically in plants and viruses that show a specific tissue tropism, which make it difficult or impossible to obtain sufficient quantities of infected tissue for RdRp isolation. Only a suitable protoplast system and a source of infectious virion RNA or virus are required. Ideally, infectious transcripts from cDNA clones would be used as inoculum because this permits tailoring of viral RNA and protein content in the protoplasts to precisely address the experimental objectives of interest, for instance detailed dissection of the viral RNA replication process. Only a low speed and high speed centrifuge and a method to infect protoplasts are required. Polyethylene glycol could be used in place of an electroporator. In the current report, we have shown that less than the full genomic complement of CCMV RNAs is sufficient for assembly of template-dependent and isolatable CCMV RdRp. Such an approach would be useful for studying RNA replication in situations in which the presence of other viral proteins (e.g., coat protein, nucleotide triphosphatase, or nuclease) could confound RdRp activity assays.

BMV RNA1 and 2 direct their own replication in protoplasts in the absence of RNA3 (10). However, previous BMV research has shown that the intercistronic and $3^{\prime}$ nontranslated regions of BMV RNA3 were required for assembly of functional BMV RdRp in yeast expressing the BMV 1a and 2a proteins (30). Although these $\mathrm{BMV}$ results and our current result of assembly of a functional and isolatable CCMV RdRp in the absence of CCMV RNA3 at first seem to contradict each other, it is important to note that in the BMV yeast expression, the 1a and 2a proteins were expressed 
A

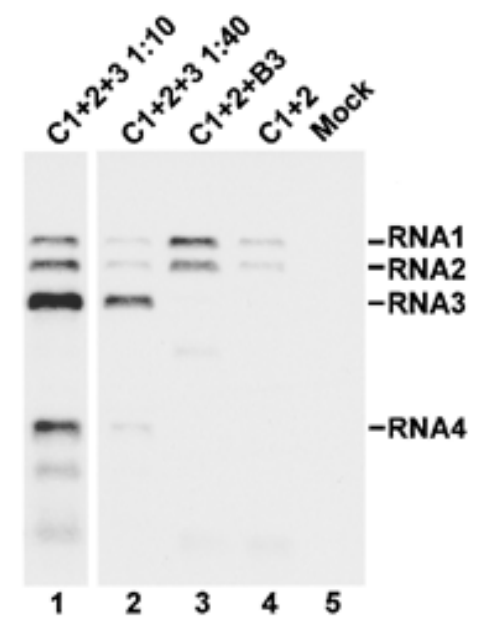

B

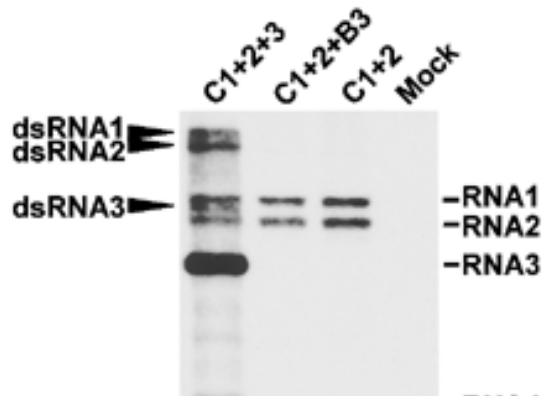

-RNA4
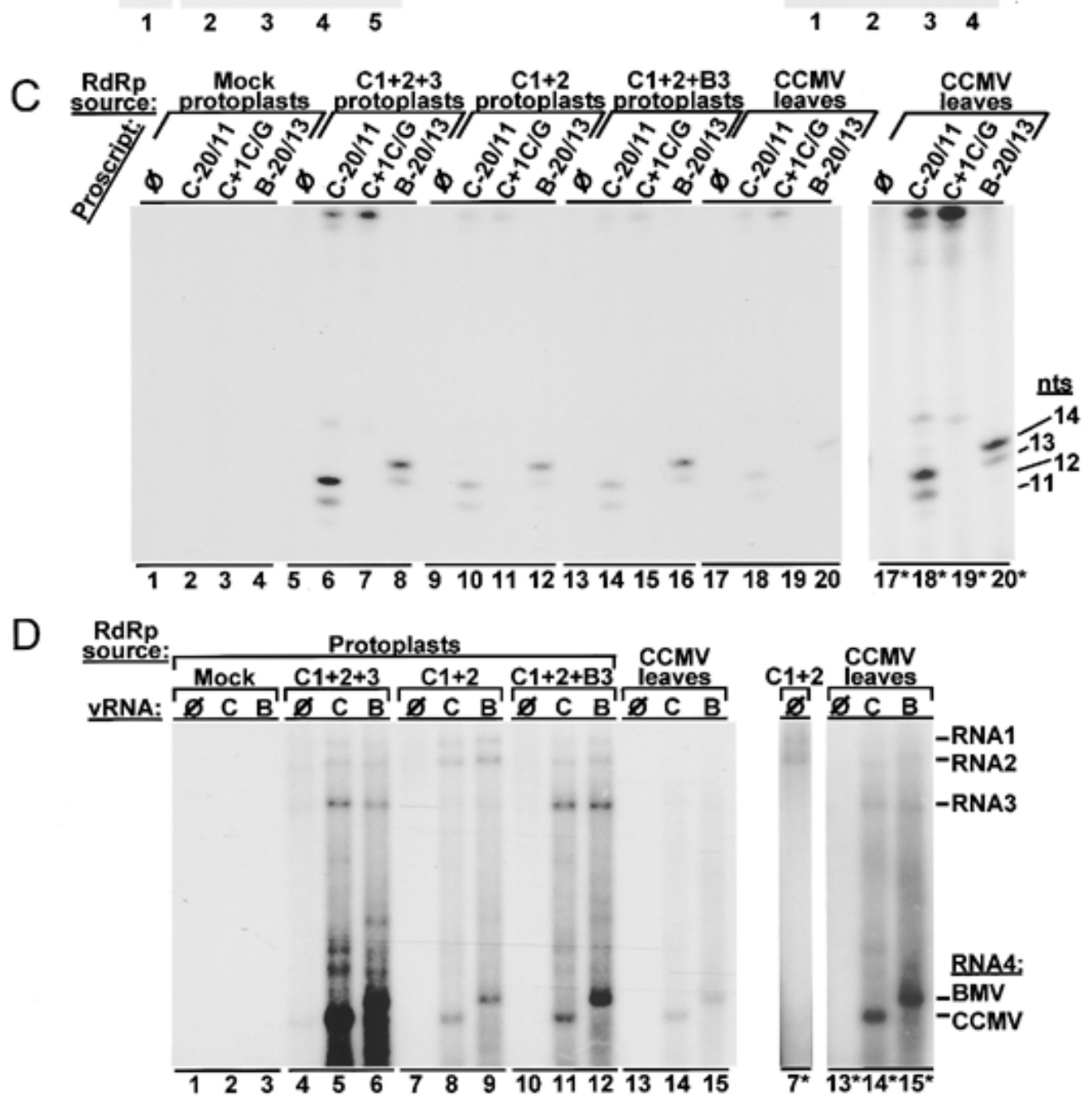

Fig. 2. Cowpea chlorotic mottle virus (CCMV) RNA1 and 2 are sufficient to direct assembly of RNA-dependent RNA polymerase (RdRp) capable of recognizing CCMV and Brome mosaic virus (BMV) subgenomic and genomic (-)-strand promoters in vitro. Accumulation of CCMV A, (+)-strand and $\mathbf{B},(-)$-strand RNAs in tobacco protoplasts 20 -h posttransfection with the combination of in vitro transcripts indicated above each lane. Lanes contain total RNA extracted from $\approx 2 \times 10^{3}$ protoplasts, except $\mathrm{C} 1+2+31 / 10$ and $\mathrm{C} 1+2+31 / 40$, which contain total RNA from $\approx 200$ and 50 protoplasts, respectively. Positions of the four CCMV RNAs are indicated to the right of each autoradiograph. Arrows to the left of the autoradiograph in B, indicate CCMV double-stranded RNA1, 2 , and 3. C, Template specificity for recognition of subgenomic promoters is identical in the presence or absence of RNA3. Products synthesized in vitro by CCMV RdRp isolated from tobacco protoplasts (transfected with CCMV RNAs 1+2, alone or in combination with CCMV or BMV RNA3) or from CCMV-infected cowpea leaves were separated by denaturing polyacrylamide gel electrophoresis and visualized by autoradiography (2.5-h exposure). The RdRp source and proscript template for each reaction are indicated above the autoradiograph where lane $\emptyset$ represents the products of a control reaction with no added template. Sizes of products in nucleotides (nts) are indicated. Lanes $17 *$ to $20^{*}$ are an 18.5-h exposure of lanes 17 to 20 . D, CCMV RdRp assembled in the absence of CCMV RNA3 is capable of recognizing CCMV and BMV (-)-strand promoters. Products synthesized in vitro from virion (v) RNA by CCMV RdRp preparations as in $\mathbf{C}$, were treated with $\mathrm{S} 1$ nuclease and resolved on a $1 \%$ nondenaturing agarose gel prior to autoradiography $(6 \mathrm{~h}$ exposure). Templates are $\mathrm{C}=$ $\mathrm{CCMV}, \mathrm{B}=\mathrm{BMV}$, and $\emptyset=$ no added template. Positions of RdRp products are indicated, including the different-sized CCMV and BMV subgenomic RNA4s (Fig. 1A). Lanes $7^{*}$ and $13^{*}$ to $15^{*}$ are a 30 -h exposure of lanes 7 and 13 to 15 . 
from $5^{\prime}$ - and $3^{\prime}$-truncated RNA1 and RNA2, which lacked promoters for (-)-strand synthesis (30). Functionally equivalent signals for BMV RdRp complex assembly must be present in BMV RNA1 or RNA2, as suggested by Quadt et al. (30). Given our present results and the established similarities between the RdRps of CCMV and BMV $(1,21)$, it is likely that the presence of any viral genomic RNA capable of directing (-)-strand synthesis is sufficient for assembly of a functional RdRp complex. These results extend the data of Quadt et al. (30) and demonstrate that CCMV RNA1 and 2 are sufficient for this purpose.

Interestingly, RdRps assembled in $\mathrm{C} 1+2+3$ and $\mathrm{C} 1+2+\mathrm{B} 3$ protoplasts utilized bromovirus (+)-strand RNA3 templates for (-)-strand synthesis more effectively than RdRp assembled in $\mathrm{C} 1+2$ protoplasts (Fig. 2D, lanes 5, 6, 11, and 12 versus lanes 8 and 9). RdRp assembled in $\mathrm{C} 1+2+3$ protoplasts utilized bromovirus (+)-strand RNA4 templates for (-)-strand synthesis more effectively than RdRps assembled in $\mathrm{C} 1+2$ and $\mathrm{C} 1+2+\mathrm{B} 3$ protoplasts (Fig. 2D, lanes 5 and 6 versus lanes 8, 9, 11, and 12). However, all three RdRps from protoplasts synthesized similar amounts of (-)-strand RNA1 and 2 (Fig. 2D, lanes 5, 6, 8, 9, 11, and 12) and subgenomic (proscript) products (Fig. 2C, lanes 6, 8, $10,12,14$, and 16). This suggests that there may be functional differences in RdRp complexes assembled in the presence or absence of RNA3 that help determine which templates can be replicated. One or more unique host factors may be a component of RdRp assembled on or in the presence of RNA3, which then contributes to more efficient recognition of RNA3 and 4 (which are of identical sequence) or synthesis of (-)-strand RNA3 and 4 in vitro. Alternatively, isolatable RdRp levels might be considerably lower in protoplasts inoculated with only CCMV RNA1 and 2 although this seems less likely because there was little change in the levels of (-)-strand RNA1 and 2 synthesized by RdRp isolated from these cells.

\section{ACKNOWLEDGMENTS}

This research was supported in part by the U.S. Department of Agriculture Grant 98-35505-6752. We thank C. Vanderspool, C. Robertson, and C. Sine for excellent technical assistance and M. E. Hilf and G. Danyluk for critical review of the manuscript.

\section{LITERATURE CITED}

1. Adkins, S., and Kao, C. C. 1998. Subgenomic RNA promoters dictate the mode of recognition by bromoviral RNA-dependent RNA polymerases. Virology 252:1-8.

2. Adkins, S., Siegel, R. W., Sun, J.-H., and Kao, C. C. 1997. Minimal templates directing accurate initiation of subgenomic RNA synthesis in vitro by the brome mosaic virus RNA-dependent RNA polymerase. RNA 3:634-647.

3. Adkins, S., Stawicki, S. S., Faurote, G., Siegel, R. W., and Kao, C. C. 1998. Mechanistic analysis of RNA synthesis by RNA-dependent RNA polymerase from two promoters reveals similarities to DNA-dependent RNA polymerase. RNA 4:455-470.

4. Ahlquist, P. 1992. Bromovirus RNA replication and transcription. Curr. Opin. Genet. Dev. 2:71-76.

5. Ahlquist, P., Luckow, V., and Kaesberg, P. 1981. Complete nucleotide sequence of brome mosaic virus RNA3. J. Mol. Biol. 153:23-38.

6. Allison, R. F., Janda, M., and Ahlquist, P. 1988. Infectious in vitro transcripts from cowpea chlorotic mottle virus cDNA clones and exchange of individual RNA components with brome mosaic virus. J. Virol. 62:3581-3588

7. Buck, K. W. 1996. Comparison of the replication of positive-stranded RNA viruses of plants and animals. Adv. Virus Res. 47:159-251.

8. Chandrika, R., Rabindran, S., Lewandowski, D. J., Manjunath, K. L., and Dawson, W. O. 2000. Full-length tobacco mosaic virus RNAs and defective RNAs have different 3' replication signals. Virology 273:198-209.

9. Cocking, E. C. 1960. A method for the isolation of plant protoplasts and vacuoles. Nature 187:927-929.

10. French, R., and Ahlquist, P. 1987. Intercistronic as well as terminal se- quences are required for efficient amplification of brome mosaic virus RNA3. J. Virol. 61:1457-1465.

11. Gal-On, A., Canto, T., and Palukaitis, P. 2000. Characterisation of genetically modified cucumber mosaic virus expressing histidine-tagged 1a and 2a proteins. Arch. Virol. 145:37-50.

12. Hardy, S. F., German, T. L., Loesch-Fries, L. S., and Hall, T. C. 1979. Highly active template-specific RNA-dependent RNA polymerase from barley leaves infected with brome mosaic virus. Proc. Natl. Acad. Sci. USA 76:4956-4960.

13. Janda, M., French, R., and Ahlquist, P. 1987. High efficiency T7 polymerase synthesis of infectious RNA from cloned brome mosaic virus cDNA and effects of $5^{\prime}$ extensions on transcript infectivity. Virology 158:259-262.

14. Kao, C. C., and Sivakumaran, K. 2000. Brome mosaic virus, good for an RNA virologist's basic needs. Mol. Plant Pathol. 1:91-97.

15. Kiberstis, P. A., Loesch-Fries, L. S., and Hall, T. C. 1981. Viral protein synthesis in barley protoplasts inoculated with native and fractionated brome mosaic virus RNA. Virology 112:804-808.

16. Lewandowski, D. J., and Dawson, W. O. 1998. Deletion of internal sequences results in tobacco mosaic virus defective RNAs that accumulate to high levels without interfering with replication of the helper virus. Virology 251:427-437.

17. Lewandowski, D. J., and Dawson, W. O. 2000. Functions of the 126- and 183-kDa proteins of tobacco mosaic virus. Virology 271:90-98.

18. Marsh, L. E., Huntley, C. C., Pogue, G. P, Connell, J. P., and Hall, T. C. 1991. Regulation of (+):(-)-strand asymmetry in replication of brome mosaic virus RNA. Virology 182:76-83.

19. Miller, W. A., Dreher, T. W., and Hall, T. C. 1985. Synthesis of brome mosaic virus subgenomic RNA in vitro by internal initiation on (-)-sense genomic RNA. Nature 313:68-70.

20. Miller, W. A., and Hall, T. C. 1983. Use of micrococcal nuclease in the purification of highly template dependent RNA-dependent RNA polymerase from brome mosaic virus-infected barley. Virology 125:236-241.

21. Miller, W. A., and Hall, T. C. 1984. RNA-dependent RNA polymerase isolated from cowpea chlorotic mottle virus-infected cowpeas is specific for bromoviral RNA. Virology 132:53-60.

22. Miller, W. A., and Koev, G. 2000. Synthesis of subgenomic RNAs by positive-strand RNA viruses. Virology 273:1-8.

23. Motoyoshi, F., Bancroft, J. B., and Watts, J. W. 1974. The infection of tobacco protoplasts with a variant of brome mosaic virus. J. Gen. Virol. 25:31-36.

24. Motoyoshi, F., Bancroft, J. B., Watts, J. W., and Burgess, J. 1973. The infection of tobacco protoplasts with cowpea chlorotic mottle virus and its RNA. J. Gen. Virol. 20:177-193.

25. Navas-Castillo, J., Albiach-Martí, M. R., Gowda, S., Hilf, M. E., Garnsey, S. M., and Dawson, W. O. 1997. Kinetics of accumulation of citrus tristeza virus RNAs. Virology 228:92-97.

26. Nitta, N., Takanami, Y., Kuwata, S., and Kubo, S. 1988. Inoculation with RNAs 1 and 2 of cucumber mosaic virus induces viral RNA replicase activity in tobacco mesophyll protoplasts. J. Gen. Virol. 69:2695-2700.

27. Okuno, T., and Furusawa, I. 1979. RNA polymerase activity and protein synthesis in brome mosaic virus-infected protoplasts. Virology 99: 218-225.

28. Osman, T. A. M., and Buck, K. W. 1996. Complete replication in vitro of tobacco mosaic virus RNA by a template-dependent, membrane-bound RNA polymerase. J. Virol. 70:6227-6234.

29. Pacha, R. F., Allison, R. F., and Ahlquist, P. 1990. Cis-acting sequences required for in vivo amplification of genomic RNA3 are organized differently in related bromoviruses. Virology 174:436-443.

30. Quadt, R., Ishikawa, M., Janda, M., and Ahlquist, P. 1995. Formation of brome mosaic virus RNA-dependent RNA polymerase in yeast requires coexpression of viral proteins and viral RNA. Proc. Natl. Acad. Sci. USA 92:4892-4896

31. Quadt, R., and Jaspars, E. M. J. 1990. Purification and characterization of brome mosaic virus RNA-dependent RNA polymerase. Virology 178:189-194.

32. Siegel, R. W., Adkins, S., and Kao, C. C. 1997. Sequence-specific recognition of a subgenomic promoter by a viral RNA polymerase. Proc. Natl. Acad. Sci. USA 94:11238-11243.

33. Sun, J.-H., Adkins, S., Faurote, G., and Kao, C. C. 1996. Initiation of (-)-strand RNA synthesis catalyzed by the BMV RNA-dependent RNA polymerase: Synthesis of oligonucleotides. Virology 226:1-12.

34. Takebe, I. 1975. The use of protoplasts in plant virology. Annu. Rev. Phytopathol. 13:105-125.

35. Taschner, P. E. M., Van Der Kuyl, A. C., Neeleman, L., and Bol, J. F. 1991. Replication of an incomplete alfalfa mosaic virus genome in plants transformed with viral replicase genes. Virology 181:445-450. 